\title{
PEMANFAATAN LUMPUR SIDOARJO SEBAGAI BAHAN CAMPURAN BETON MUTU RENDAH
}

\author{
Lies K. Wulandari(1), Sudirman Indra(2) \\ (1)Teknik Sipil Konsentrasi Manajemen Konstruksi, Institut Teknologi Nasional Malang \\ Email: lieskwulandari@gmail.com \\ (2) Teknik Sipil Institut Teknologi Nasional Malang
}

\begin{abstract}
ABSTRAK
Permasalahan utama yang melatar belakangi penelitian ini adalah bencana luapan lumpur panas Sidoarjo di Desa Renokenongo, Kecamatan Porong, Kabupaten Sidoarjo sejak. Penggunaan material bahan bangunan pada beton yang masih menggunakan sumber daya alam yang tidak dapat diperbarui seperti semen, pasir dan lain-lain. Maka diperlukan upaya untuk memanfaatkan lumpur Sidoarjo untuk campuran pembuatan campuran beton mutu rendah sebagai sumbangan pikiran dalam menangani bencana LUSI serta melakukan upaya menghindari kelangkaan sumber daya alam di masa mendatang dengan memanfaatkan LUSI sebagai campuran tambahan lainnya. Pada penelitian ini akan dilakukan pengembangan dari penelitian-penelitian sebelumnya tentang lumpur Sidoarjo yaitu pembuatan campuran beton mutu rendah. Penelitian ini diharapkan dapat memberikan hasil yang lebih maksimal dalam pembuatan campuran beton mutu rendah.
\end{abstract}

Kata kunci: Lumpur Sidoarjo, Beton mutu rendah, substitusi Pasir

\section{PENDAHULUAN}

Perkembangan teknologi dalam bidang konstruksi dari tahun ke tahun semakin pesat, baik dari segi desain maupun metode-metode konstruksi yang dilakukan. Dalam pekerjaan konstruksi beton, pemadatan beton adalah pekerjaan yang mutlak dan harus dilakukan untuk suatu pekerjaan struktur beton bertulang konvensional. Tujuan dari pemadatan itu sendiri adalah meminimalkan udara yang terjebak di dalam beton segar, sehingga diperoleh beton yang homogen dan tidak terjadi rongga-rongga di dalam beton (honey-comb). Konsekuensi dari beton bertulang yang tidak sempurna dalam pemadatan, diantaranya dapat menurunkan kuat tekan beton dan impermeabilitas beton sehingga mudah terjadi korosi pada besi tulangan (Sugiharto dan Kusuma, 2001).

Beton terdiri atas agregat semen dan air yang dicampur bersama-sama dalam keadaan plastis dan mudah untuk dikerjakan. Karena sifat ini menyebabkan beton mudah untuk dibentuk sesuai dengan yang direncanakan. setelah pencampuran, adukan terjadi reaksi kimia yang pada umumnya bersifat hidrasi dan menghasilkan suatu pengerasan dan pertambahan kekuatan. Menurut Mulyono (2006) campuran beton terdiri dari bahan semen hidrolik, agregat kasar, agregat halus, air, dan bahan tambah, sedangkan menurut Sagel dkk (1994) beton adalah suatu komposit dari bahan batuan yang direkatkan oleh bahan ikat. Semen mempengaruhi kecepatan pengerasan beton.

Menurut SNI 03-6468-2000 mutu beton terdiri dari tiga kategori yaitu beton mutu rendah, beton mutu sedang, dan beton mutu tinggi. Beton mutu rendah terbagi menjadi dua bagian yaitu beton mutu rendah yang memiliki kuat tekan 10-15 MPa dan pada umumnya digunakan sebagai lantai kerja, sedangkan beton mutu rendah yang memiliki kuat tekan 16-20 MPa pada umumnya digunakan untuk struktur tanpa tulangan seperti siklop, trotoar dan pasangan batu kosong yang diisi adukan, pasangan batu. Beton mutu sedang memiliki kuat tekan sekitar 221-40 MPa yang digunakan untuk beton bertulang seperti pelat lantai jembatan, gelagar beton bertulang, diafragma, kerb beton pracetak, gorong-gorong beton bertulang, dan bangunan bawah jembatan. Sedangkan untuk beton mutu tinggi yang memiliki kuat tekan >41 MPa pada umumnya digunakan untuk beton prategang seperti tiang pancang, gelagar beton prategang, pelat beton prategang dan sejenisnya.

\section{TINJAUAN PUSTAKA}




\section{Kuat Tekan Beton}

Kuat tekan beton adalah besarnya beban maksimum persatuan luas atau parameter yang menunjukan besarnya beban yang dapat ditahan persatuan luas, yang menyebabkan benda uji beton hancur bila dibebani dengan gaya tekan tertentu yang dihasilkan oleh mesin tekan. Kuat tekan beton merupakan salah satu sifat penting untuk menentukan mutu beton, sedangkan kualitas beton itu sendiri yang ditentukan oleh perbandingan semen, agregat halus, agregat kasar, air dan berbagai jenis bahan tambahan. Perbandingan jumlah air dan jumlah semen atau biasa disebut faktor air semen, merupakan faktor penting yang mempengaruhi kekutan beton. Semakin kecil nilai faktor air semennya, maka semakin tinggi kuat tekan beton sedangkan semakin besar jumlah air yang digunakan akan meningkatkan kemudahan pengerjaan, akan tetapi akan menurunkan nilai kekuatan tekan.

Kuat tekan beton merupakan gambaran dari mutu beton yang berkaitan dengan truktur beton. Kuat tekan beton merupakan parameter terpenting adalah beton lebih tahan terhadap tekan dari pada tarik (Tjokrodimuljo,K,1996).

Alat untuk pengujian tekan yang digunakan adalah mesin uji multi guna (Universal Testing Machine). Prosedur pengujian menggunakan satandar ASTM C39-86 (Standard Test Method for Compressive Strength of Cylindrical Concrete Specimens) dan ASTM C 684-89 Standard Test Method for Making, Accelerated Curing and Testing Concrete Compression Test Specimens). Untuk mendapatkan bidang kontak tekan yang benarbenar rata, maka benda uji akan diberi lapisan material khusus (capping layer) dengan tebal antara 1,5-3,0 mm dan disyaratkan tidak akan mempengaruhi pembacaan tes kuat tekan beton. 40 Beban yang berkerja akan terdistribusi secara merata melalui titik berat penampang sepanjang sumbu longitudinal dengan tegangan sebesar:

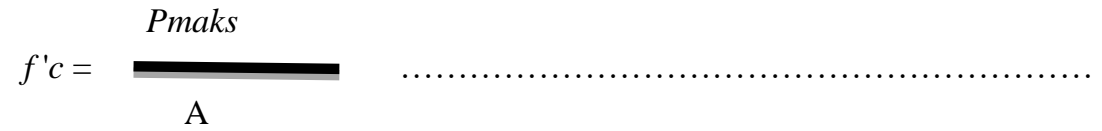

dengan:

$f^{\prime} c=$ Kuat tekan silinder beton $(\mathrm{N} / \mathrm{mm} 2=\mathrm{MPa})$

Pmaks = Beban tekan maksimum $(\mathrm{N})$

$A \quad=$ Luas penampang benda uji $(\mathrm{mm} 2)$

Faktor-faktor yang mempengaruhi kuat tekan beton adalah:

a. Faktor air semen

b. Umur beton

Menurut P. Kumar Mehta Paulo \& J.M. Monteiro (2006) beton mempunyai kekuatan rendah jika kuat tekannya kurang dari $20 \mathrm{MPa}$, berkekuatan sedang jika antara 20-40 MPa dan beton berkekuatan tinggi jika mempunyai kuat tekan lebih besar dari $40 \mathrm{MPa}$.

Menurut Tjokrodimuljo,K (2007) jika beton mempunyai kuat tekan tinggi, umumnya sifat-sifat yang lain juga baik. Berdasarkan kuat tekannya, beton dapat dibagi menjadi beberapa jenis, diantaranya beton sederhana mempunyai kuat tekan sampai $10 \mathrm{MPa}$, beton normal mempunyai kuat tekan antara 15-30 MPa, beton prategang mempunyai kuat tekan 30-40 MPa, beton kuat tekan tinggi mempunyai kuat tekan antara 40-80 $\mathrm{MPa}$ dan beton kuat tekan sangat tinggi mempunyai kuat tekan diatas $80 \mathrm{MPa}$.

\section{METODOLOGI PENELITIAN Diagram Alir Penelitian}

Penelitian ini dilakukan dengan melalui menempuh rangkaian kegiatan sebagaimana dijelaskan pada diagram alir berikut: 
JURNAL INFOMANPRO

p-ISSN 2460-9609

e-ISSN 2774-7956

https://ejournal.itn.ac.id/index.php/infomanpro

vol.10 No.1 Tahun 2021 , pp. 16-22

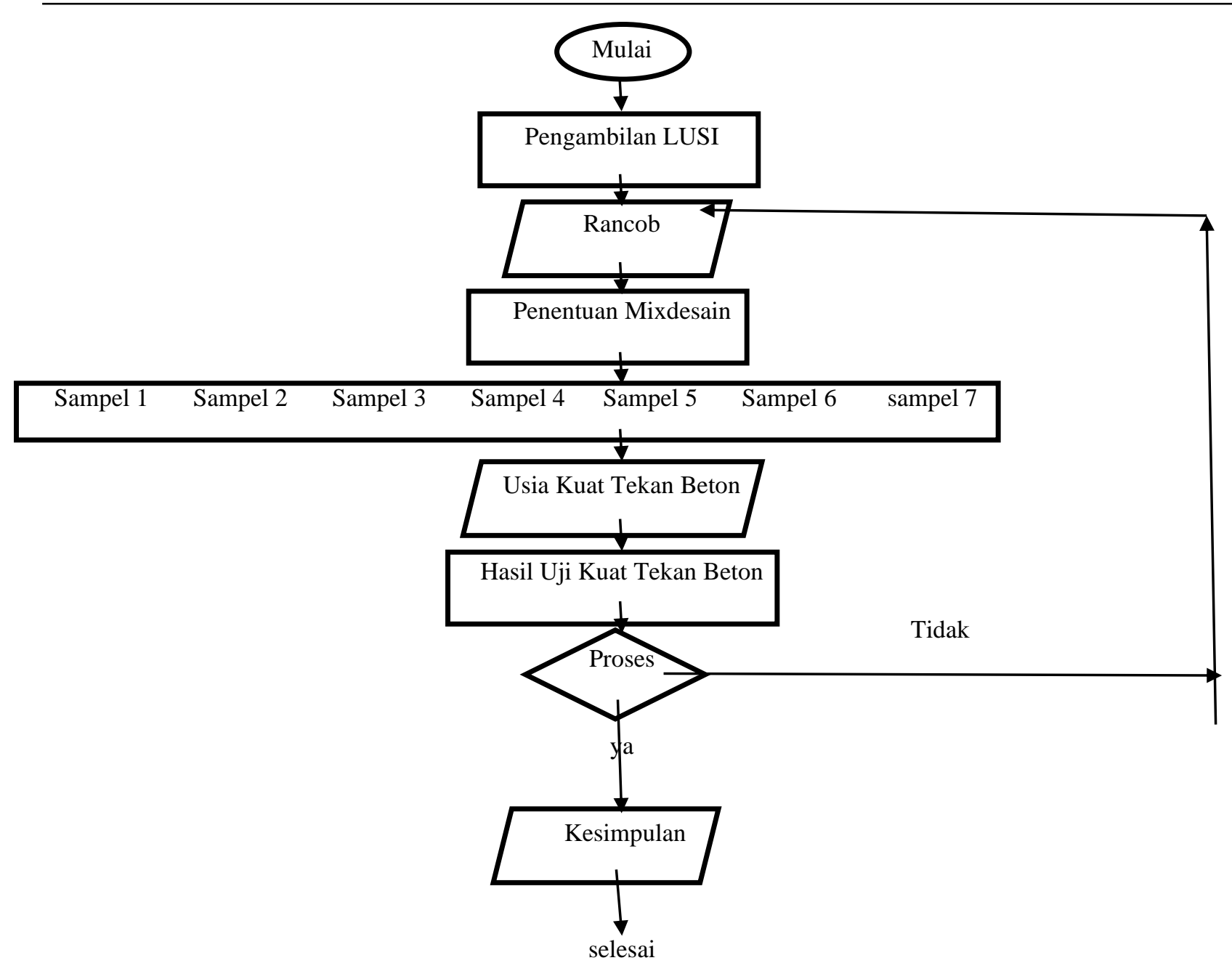

Gambar 1. Diagram Alir Penelitian

\section{Keterangan Diagram alir}

a) Pengambilan LUSI

Pengambilan sampel lumpur sidoarjo dilakukan dengan tujuan sebagai substitusi pasir guna pemanfaatan material tersebut

b) Rancob (Rancangan Percobaan)

Rancangan percobaan dilaksanakan sebelum uji laboratorium guna dapat mendisain campuran yang digunakan untuk mencapai mutu beton yang diinginkan.

c) Penentuan Mixdesain

Dari hasil Rncangan Percobaan maka dibuatlah camuran berdasarkan berat

d) Sampel

Sampel dibuat $7+2$ asli (LUSI murni dan Beton murni)

e) Usia Kuat Tekan Beton

Usia test beton dibuat 28 hari

f) Hasil Uji Kuat Tekan Beton

Test beton dilakukan pada laboratorium Brawijaya

g) Proses

Proses yang dimaksud adalah hasil uji lab. Memenuhi syarat atau tidaknya. 


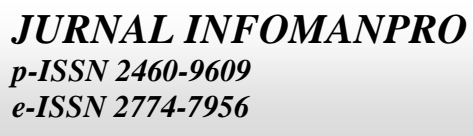

https://ejournal.itn.ac.id/index.php/infomanpro vol.10 No.1 Tahun 2021 , pp. 16-22

\section{HASIL PENELITIAN DAN PEMBAHASAN \\ Pengambilan Lusi}

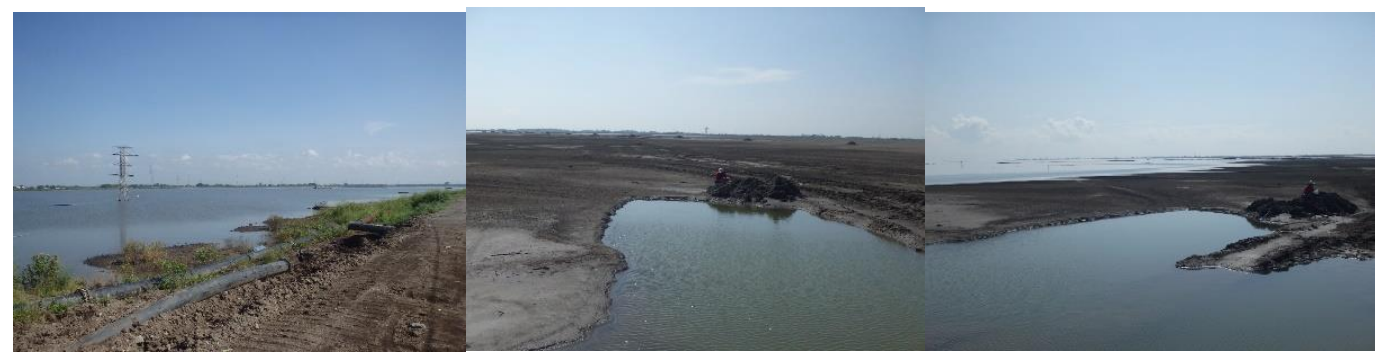

Gambar 2. Pengambilan Lumpur Sidoarjo

Pengambilan lumpur sidoarjo dilakukan melalui petugas setempat dengan jumlah sesuai kebutuhan substitusi pasir sebagai campuran beton.

\section{Rancangan Percobaan (Rancob)}

Tabel 1. Rancob Penelitian

\begin{tabular}{|c|c|c|c|c|c|c|c|c|c|c|}
\hline \multirow[b]{2}{*}{ Perlakuan } & \multicolumn{4}{|c|}{ Komposisi } & \multirow{2}{*}{$\begin{array}{l}\text { Total } \\
\text { Berat }\end{array}$} & \multicolumn{4}{|c|}{ Tes Beton (Mutu) } & \multirow[b]{2}{*}{ Prediks } \\
\hline & Lumpur & Semen & Kerikil & Air & & $\begin{array}{l}\text { Ul } \\
1\end{array}$ & $\mathrm{Ul} 2$ & Ul 3 & Rata-rata & \\
\hline P1 & 2200 & 1200 & 900 & 1000 & 5300 & $\begin{array}{l}22 \\
7\end{array}$ & 242 & 234 & 234.33 & 226.18 \\
\hline P2 & 2200 & 1200 & 1000 & 1000 & 5400 & $\begin{array}{l}22 \\
5\end{array}$ & 227 & 214 & 222.00 & 229.03 \\
\hline P3 & 2200 & 1200 & 1100 & 1000 & 5500 & $\begin{array}{l}22 \\
2\end{array}$ & 233 & 242 & 232.33 & 232.00 \\
\hline P4 & 2200 & 1300 & 900 & 1000 & 5400 & $\begin{array}{l}25 \\
0\end{array}$ & 242 & 247 & 246.33 & 245.28 \\
\hline P5 & 2200 & 1300 & 1000 & 1000 & 5500 & $\begin{array}{l}24 \\
0\end{array}$ & 238 & 260 & 246.00 & 248.13 \\
\hline P6 & 2200 & 1300 & 1100 & 1000 & 5600 & $\begin{array}{l}25 \\
1\end{array}$ & 250 & 246 & 249.00 & 251.10 \\
\hline P7 & 2200 & 1400 & 900 & 1000 & 5500 & $\begin{array}{l}26 \\
5\end{array}$ & 272 & 273 & 270.00 & 267.38 \\
\hline P8 & 2200 & 1400 & 1000 & 1000 & 5600 & $\begin{array}{l}25 \\
9\end{array}$ & 270 & 278 & 269.00 & 270.23 \\
\hline P9 & 2200 & 1400 & 1100 & 1000 & 5700 & $\begin{array}{l}26 \\
7\end{array}$ & 275 & 280 & 274.00 & 273.20 \\
\hline P10 & 2300 & 1200 & 900 & 1000 & 5400 & $\begin{array}{l}20 \\
3\end{array}$ & 218 & 212 & 211.00 & 209.88 \\
\hline P11 & 2300 & 1200 & 1000 & 1000 & 5500 & $\begin{array}{l}22 \\
1\end{array}$ & 208 & 206 & 211.67 & 212.73 \\
\hline P12 & 2300 & 1200 & 1100 & 1000 & 5600 & $\begin{array}{l}20 \\
6\end{array}$ & 226 & 216 & 216.00 & 215.70 \\
\hline P13 & 2300 & 1300 & 900 & 1000 & 5500 & $\begin{array}{l}23 \\
7\end{array}$ & 231 & 220 & 229.33 & 228.98 \\
\hline P14 & 2300 & 1300 & 1000 & 1000 & 5600 & $\begin{array}{l}23 \\
4\end{array}$ & 236 & 243 & 237.67 & 231.83 \\
\hline
\end{tabular}




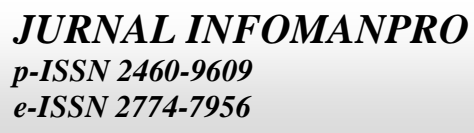

https://ejournal.itn.ac.id/index.php/infomanpro vol.10 No.1 Tahun 2021 , pp. 16-22

\begin{tabular}{|l|l|l|l|l|l|l|l|l|l|l|} 
P15 & 2300 & 1300 & 1100 & 1000 & $\mathbf{5 7 0 0}$ & $\begin{array}{l}22 \\
5\end{array}$ & 228 & 232 & $\mathbf{2 2 8 . 3 3}$ & $\mathbf{2 3 4 . 8 0}$ \\
\hline P16 & 2300 & 1400 & 900 & 1000 & $\mathbf{5 6 0 0}$ & $\begin{array}{l}24 \\
5\end{array}$ & 239 & 242 & $\mathbf{2 4 2 . 0 0}$ & $\mathbf{2 5 1 . 0 8}$ \\
\hline P17 & 2300 & 1400 & 1000 & 1000 & $\mathbf{5 7 0 0}$ & $\begin{array}{l}25 \\
6\end{array}$ & 262 & 257 & $\mathbf{2 5 8 . 3 3}$ & $\mathbf{2 5 3 . 9 3}$ \\
\hline P18 & 2300 & 1400 & 1100 & 1000 & $\mathbf{5 8 0 0}$ & $\begin{array}{l}26 \\
8\end{array}$ & 254 & 262 & $\mathbf{2 6 1 . 3 3}$ & $\mathbf{2 5 6 . 9 0}$ \\
\hline P19 & 2400 & 1200 & 900 & 1000 & $\mathbf{5 5 0 0}$ & $\begin{array}{l}19 \\
1\end{array}$ & 193 & 180 & $\mathbf{1 8 8 . 0 0}$ & $\mathbf{1 8 9 . 1 4}$ \\
\hline P20 & 2400 & 1200 & 1000 & 1000 & $\mathbf{5 6 0 0}$ & $\begin{array}{l}18 \\
0\end{array}$ & 192 & 210 & $\mathbf{1 9 4 . 0 0}$ & $\mathbf{1 9 1 . 9 9}$ \\
\hline P21 & 2400 & 1200 & 1100 & 1000 & $\mathbf{5 7 0 0}$ & $\begin{array}{l}19 \\
3\end{array}$ & 195 & 188 & $\mathbf{1 9 2 . 0 0}$ & $\mathbf{1 9 4 . 9 6}$ \\
\hline P22 & 2400 & 1300 & 900 & 1000 & $\mathbf{5 6 0 0}$ & $\begin{array}{l}20 \\
6\end{array}$ & 204 & 212 & $\mathbf{2 0 7 . 3 3}$ & $\mathbf{2 0 8 . 2 4}$ \\
\hline P23 & 2400 & 1300 & 1000 & 1000 & $\mathbf{5 7 0 0}$ & $\begin{array}{l}22 \\
8\end{array}$ & 216 & 199 & $\mathbf{2 1 4 . 3 3}$ & $\mathbf{2 1 1 . 0 9}$ \\
\hline P24 & 2400 & 1300 & 1100 & 1000 & $\mathbf{5 8 0 0}$ & $\begin{array}{l}20 \\
7\end{array}$ & 218 & 220 & $\mathbf{2 1 5 . 0 0}$ & $\mathbf{2 1 4 . 0 6}$ \\
\hline P25 & 2400 & 1400 & 900 & 1000 & $\mathbf{5 7 0 0}$ & $\begin{array}{l}22 \\
2\end{array}$ & 236 & 225 & $\mathbf{2 2 7 . 6 7}$ & $\mathbf{2 3 0 . 3 4}$ \\
\hline P26 & 2400 & 1400 & 1000 & 1000 & $\mathbf{5 8 0 0}$ & $\begin{array}{l}23 \\
1\end{array}$ & 234 & 222 & $\mathbf{2 2 9 . 0 0}$ & $\mathbf{2 3 3 . 1 9}$ \\
\hline P27 & 2400 & 1400 & 1100 & 1000 & $\mathbf{5 9 0 0}$ & $\begin{array}{l}24 \\
5\end{array}$ & 244 & 234 & $\mathbf{2 4 1 . 0 0}$ & $\mathbf{2 3 6 . 1 6}$ \\
\hline
\end{tabular}

Data uji coba tes mutu beton dengan komposisi lumpur, semen, kerikil, dan air. Komposisi lumpur terdiri dari 3 perlakuan yaitu $2200 \mathrm{~kg}, 2300 \mathrm{~kg}$, dan $2400 \mathrm{~kg}$; komposisi semen terdiri dari 3 perlakuan yaitu $1200 \mathrm{~kg}, 1300$ $\mathrm{kg}$, dan $1400 \mathrm{~kg}$; komposisi kerikil terdiri dari 3 perlakuan yaitu $900 \mathrm{~kg}, 1000 \mathrm{~kg}$, dan $1000 \mathrm{~kg}$.

Hasil pemodelan belum maksimal karena tidak adanya data asli hasil pengujian, sehingga sementara diperoleh grafik sebagai berikut:

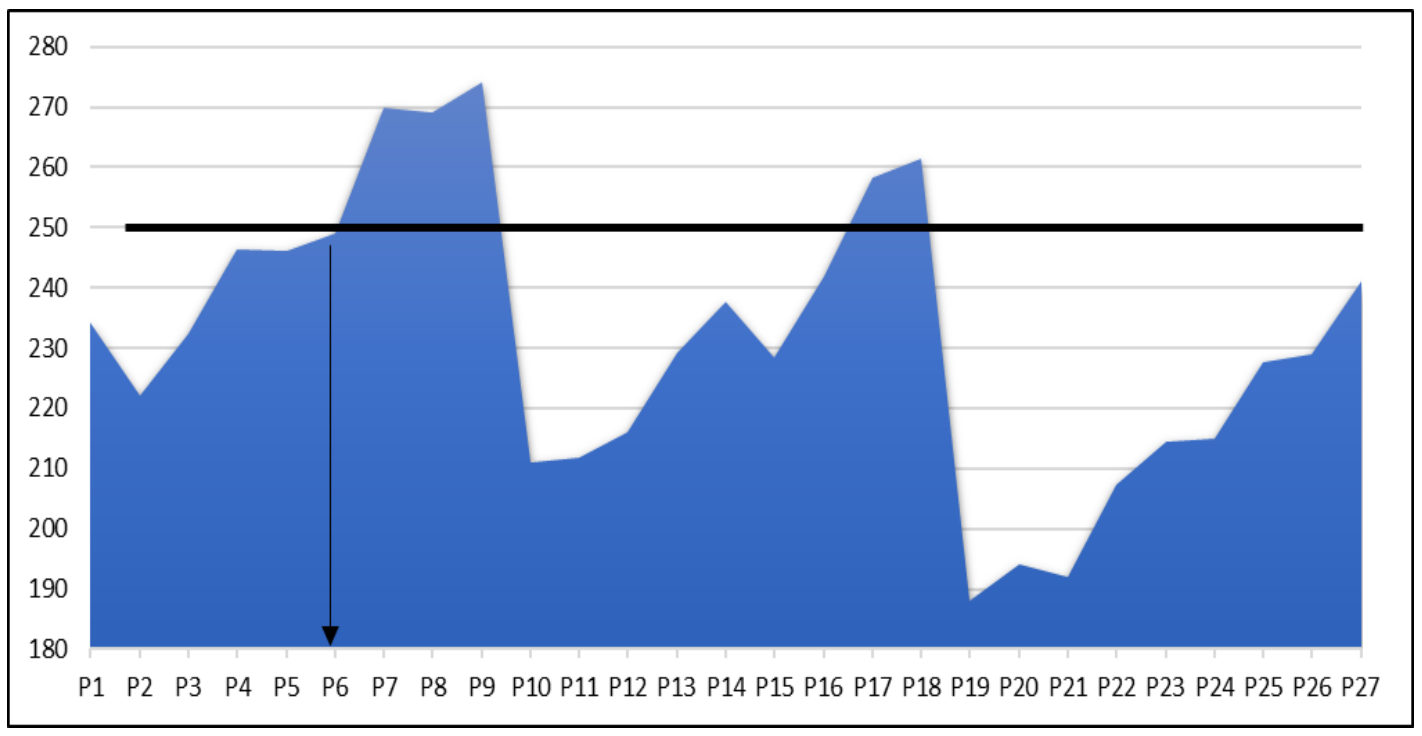

Gambae 3. Kesimpulan sementara hasil pemodelan 
https://ejournal.itn.ac.id/index.php/infomanpro

vol.10 No.1 Tahun 2021 , pp. 16-22

Berdasarkan grafik tersebut dapat diperoleh kesimpulan sementara bahwa komposisi terbaik adalah dengan menggunakan lumpur $2200 \mathrm{~kg}$, semen $1300 \mathrm{~kg}$, kerikil $1100 \mathrm{~kg}$, dan air $1000 \mathrm{~kg}$ sehingga menghasilkan tes mutu K sebesar 249,00 atau secara prediksi model sebesar 251,10.

Persamaan yang diperoleh adalah sebagai berikut:

Mutu $=-554,444+0,836 *$ Lumpur $-0,000222 *$ Lumpur $^{2}-0,184 *$ Semen $+0,00015 *$ Semen $^{2}+0,018 *$ Kerikil $+0,00000556 *$ Kerikil $^{2}+\mathrm{e}$

\section{Pembuatan Sampel}

Tabel 2. Rencana Penelitian Lumpur Lapindo

K 250 50 Vol $: 5298,75 \mathrm{~cm}^{3}$
\begin{tabular}{|l|l|l|l|l|l|}
\hline KODE & \multicolumn{6}{l}{ KOMPOSISI } & lumpur \\
\hline \multirow{2}{*}{ Perlakuan } & pasir & semen & kerikil & air & Kg \\
\cline { 2 - 6 } & Kg & Kg & Kg & Kg & 0.0000 \\
\hline ORI 1 & 3.666735 & 2.03472 & 5.505401 & 1.14 & 1.0817 \\
\hline ORI 2 & 0.00 & 0.00 & 0.00 & 1.14 & 0.2980 \\
\hline P1 & 0 & 2.03 & 5.51 & 1.14 & 0.2980 \\
\hline P2 & 0 & 2.13 & 5.51 & 1.14 & 0.3980 \\
\hline P3 & 0 & 2.13 & 5.31 & 1.14 & 0.3980 \\
\hline P4 & 0 & 2.13 & 5.41 & 1.14 & 0.4980 \\
\hline P5 & 0 & 1.93 & 5.31 & 1.14 & 2.971743 \\
\hline Total & 3.666735 & 12.38944 & 32.5508 & 7.977694 & \\
\hline
\end{tabular}

Uji Kuat Tekan Beton Pada Usia 28 Hari

Tabel 3. Hasil Tes Beton Dengan Substitusi Lusi

\begin{tabular}{|l|l|l|l|l|l|l|l|l|}
\hline NO & $\begin{array}{l}\text { Tanggal } \\
\text { Pembuatan }\end{array}$ & $\begin{array}{l}\text { Tanggal } \\
\text { Test Beton }\end{array}$ & $\begin{array}{l}\text { Umur } \\
\text { Hari }\end{array}$ & $\begin{array}{l}\text { Berat } \\
\text { Kg }\end{array}$ & $\begin{array}{l}\text { Berat } \\
\mathbf{P} \\
\mathbf{k N}\end{array}$ & $\begin{array}{l}\text { Kuat } \\
\text { Tekan } \\
\mathbf{f c} \\
\mathbf{( k g / c m} 2)\end{array}$ & $\begin{array}{l}\text { Kuat tekan } \\
\mathbf{f c}(\mathbf{k g} / \mathbf{c m} 2) \\
\mathbf{2 8} \text { hari }\end{array}$ & $\begin{array}{l}\text { Kuat tekan } \\
\text { Konversi kubus } \\
\text { (kg/cm2) }\end{array}$ \\
\hline 1 & $15 / 4 / 2021$ & $13 / 5 / 2021$ & 28 & 10.74 & 109.00 & 62.94 & 62.94 & 75.83 \\
\hline 2 & $15 / 4 / 2021$ & $13 / 5 / 2021$ & 28 & 11,41 & 169.00 & 97.59 & 97.59 & 117.57 \\
\hline 3 & $15 / 4 / 2021$ & $13 / 5 / 2021$ & 28 & 8,84 & 13.00 & 7.51 & 7.51 & 9.04 \\
\hline 4 & $15 / 4 / 2021$ & $13 / 5 / 2021$ & 28 & 9,68 & 18.00 & 10.39 & 10.39 & 12.52 \\
\hline 5 & $15 / 4 / 2021$ & $13 / 5 / 2021$ & 28 & 9,74 & 16.00 & 9.24 & 9.24 & 11.13 \\
\hline 6 & $15 / 4 / 2021$ & $13 / 5 / 2021$ & 28 & 8,74 & 10.00 & 5.77 & 5.77 & 6.96 \\
\hline 7 & $15 / 4 / 2021$ & $13 / 5 / 2021$ & 28 & 9,36 & 13.00 & 7.51 & 7.51 & 9.04 \\
\hline 8 & $15 / 4 / 2021$ & $13 / 5 / 2021$ & 28 & 8,58 & 9.00 & 5.20 & 5.20 & 6.26 \\
\hline
\end{tabular}


JURNAL INFOMANPRO

p-ISSN 2460-9609

e-ISSN 2774-7956

https://ejournal.itn.ac.id/index.php/infomanpro vol.10 No.1 Tahun 2021 , pp. 16-22

\begin{tabular}{|l|l|l|l|l|l|l|l|l|}
9 & $15 / 4 / 2021$ & $13 / 5 / 2021$ & 28 & 8,82 & 13.00 & 7.51 & 7.51 & 9.04 \\
\hline 10 & $15 / 4 / 2021$ & $13 / 5 / 2021$ & 28 & 8,97 & 18.00 & 10.39 & 10.39 & 12.52 \\
\hline 11 & $15 / 4 / 2021$ & $13 / 5 / 2021$ & 28 & 8,66 & 10.00 & 5.77 & 5.77 & 6.96 \\
\hline 12 & $15 / 4 / 2021$ & $13 / 5 / 2021$ & 28 & 8,67 & 9.00 & 5.20 & 5.20 & 6.26 \\
\hline
\end{tabular}

\section{Hasil Uji Kuat Tekan Beton}

Berdasarkan hasil uji test beton di atas, maka nilai maksimal 117 dan campuran Lusi didapatkan nilai 12,52 sehingga hanya dapat digunakan dengan beton mutu rendah yaitu "Lantai Kerja"

\section{KESIMPULAN}

Dari hasil penelitian dan pembahasan tersebut di atas dapat disimpulkan beberapa hal sebagai berikut:

a. Hasil test beton menunjukkan bahwa Lusi bisa digunakan dengan baton mutiu rendah

b. Beton mutu rendah yaitu lebih cocok digunakan sebagai lantai kerja

c. Prosentase Lusi dapat difariasikan sampai maksimal mendapatkan mutu beton yang direrncanakan.

\section{DAFTAR PUSTAKA}

ASTM C 128-78, Standard Test Method for Density, Relative Density (Spesific Gravity), and Absorbtion of Fine Aggregate

ASTM C 128-93, Standard Test Method for Density, Relative Density (Spesific Gravity), and Absorbtion of Fine Aggregate

Dibiantara, Dimas Pustaka. (2013). Pemanfaatan Lumpur Bakar Sidoarjo Untuk Beton Ringan Dengan Campuran Fly Ash, Foam, Dan Serat Kenaf (http://digilib.its.ac.id/pemanfaatan-lumpur-bakarsidoarjountuk-beton-ringan-dengan-campuran-fly-ashfoam-dan-serat-kenaf-25189.html). Surabaya: ITS Library, RSS 620.136 Dib p.

Febrian, Lericta. (2012) Pemanfaatan Lumpur Oven Sidoarjo Sebagai Bahan Campuran Pembuatan Beton Ringan Dengan Tambahan Pasta Foam 